\title{
Consequences of Sport-Imposed Weight Restriction in Childhood
}

\author{
Nathalie Boisseau \\ LAPHAP, Faculté des Sciences du Sport, Poitiers, France
}

\author{
Key Words \\ Childhood sport • Weight restriction - Growth, childhood • \\ Maturation
}

\begin{abstract}
Today, young competitors undertake training programs including a high level of physical activity from an early age. This intensive training (volume and intensity) increases energy expenditure which has to be compensated by a greater nutritional intake. Ballet dancers, figure skaters, gymnasts or rhythmic gymnasts start training at the age of 5-6 years and most of them practice more than 20-30 h/week. In these activities, as well as for weight-class sports (wrestlers, jockeys, judo or boxing athletes), young elite athletes make conscious decisions to reduce food intakes to maintain the slender, pre-pubertal physique or to 'make weight'. Adequate energy and micronutrient intakes are essential for growing children, and caloric and fluid restrictions during physical training in childhood or during adolescence could disturb metabolic and hormonal regulations affecting growth, maturation, body composition, menstrual cycle and reproductive capacity, and may increase the risk of injuries such as stress fractures. Furthermore, these strategies may develop eating disorders (anorexia and/or bulimia nervosa), especially during female adolescence, affecting body image, self-image and developing social and emotional maladjustments.
\end{abstract}

Copyright ๑ 2006 Nestec Ltd., Vevey/S. Karger AG, Basel
(C) 2006 Nestec Ltd., Vevey/S. Karger AG, Basel 0517-8606/06/0642-0077\$23.50/0

Fax +41613061234

E-Mail karger@karger.ch

www.karger.com
Accessible online at: www.karger.com/ane

\section{Introduction}

During childhood and adolescence, rapid growth and development increase energy and micronutrient requirements. The nutritional needs are greater in young athletes due to the higher level of physical activity. Food and fluid restrictions in young elite athletes are extensive, especially in aesthetic and weight-class sports, and may potentially be dangerous during the growing period. The aim of this review is to report the potential adverse health effects of sport-imposed weight restriction in childhood.

\section{Food and Fluid Restrictions in Specific Sport Categories}

\section{Energy, Macro- and Micronutrients}

During childhood and adolescence, rapid growth and development affect energy, macro- and micronutrient needs.

\section{Energy}

Due to great intra- and inter-individual variability, there are some difficulties to quantify the estimated energy requirements in the athletic or very active child or adolescent. The Food and Nutrition Board's calculation for the estimated energy requirements is based on equa- 
tions including an individual's age, height, body weight and a physical classification of sedentary, moderately active, active, and very active life style [1]. Among 9- to 13year-old children, energy needs range from $1,415 \mathrm{kcal} /$ day for the sedentary 9-year-old girl to 3,038 kcal/day for the very active 13-year-old boy. Among 14- to 18-year-old adolescents, energy requirements range from $1,718 \mathrm{kcal} /$ day for the sedentary 14-year-old girl to $3,804 \mathrm{kcal} /$ day for the very active adolescent of 18 years. Thus, the total energy expenditure in child and adolescent athletes is linked to basal energy, growth and the level of physical activity. For example, in elite gymnasts, physical training increases caloric demands and induces an additional 400$700 \mathrm{kcal}$ energy intake/day [2,3].

\section{Energy Intake in Sports with Weight Restriction}

In order to remain lean and to keep a juvenile physique, many elite gymnasts, rhythmic gymnasts, ballet dancers and figure skaters are convinced that they have to be on a diet. In weight-classification sports (wrestlers, judo or boxing athletes), food and fluid intake restrictions are commonly practiced throughout the competitive season to compete at one to three weight classes below their normal weight [4] in the belief that they will gain a competitive advantage over smaller opponents. Thus, repeated cycles of weight loss and regain are usual and the energy intakes are regularly disturbed $[5,6]$. These 'weight cuttings' and regains have been associated with reduced energy requirements due to a decreased metabolic rate in young athletes [7].

Although limited, a few studies have shown that all along the training program (gymnasts, rhythmic gymnasts, ballet dancers, etc.) or throughout the competitive season for weight-class athletes, the energy intake is theoretically insufficient to support growth and vigorous training [8-20].

\section{Protein}

Sufficient protein intake is required to provide essential amino acids which support growth, and especially the maintenance and development of lean body mass. Indeed, protein metabolism is important for lean tissue growth and remodeling. Heavy and regular exercise training increases the daily protein requirements in adult athletes [ 1 , 21]. Recommended protein intakes for sedentary or moderately active children and adolescents (between 9 and 18 years) range from 0.73 to $0.85 \mathrm{~g} / \mathrm{kg}$ [1] or 0.80 to $1.0 \mathrm{~g} / \mathrm{kg}$ body mass [22,23]. However, this recommendation is not based on active or very active children. Actually, no data are available on the protein requirements of young ath- letes. In most cases, young competitors spontaneously increase their food intake for energy and naturally meet their protein needs. In sports leading to food restriction behaviors, protein metabolism could be disturbed and thus, impair growth and/or total fat-free mass.

In gymnasts or ballerinas, even if nutritional assessments indicate that many of these young girls have a caloric intake inferior to the usual recommended dietary allowance [1] for their age and physical activity level [17, 24-27], the protein intake spontaneously appears to be greater than $0.8-1.0 \mathrm{~g} / \mathrm{kg} /$ day and most of the time reaches $1.3-1.8 \mathrm{~g} / \mathrm{kg} /$ day. In fact, as reported in different nutrition studies, these athletes consume excess protein at the expense of fat and carbohydrates [27]. Furthermore, a recent study using the stable isotope ${ }^{15} \mathrm{~N}$-glycine indicates that training does not affect protein turnover in pre- and early pubertal female gymnasts [17].

The attitude concerning young elite wrestlers or judo athletes is quite different. Thus, different publications have shown that the nutritional protein status may be altered during the period of 'weight cutting' [28], which could induce a temporary negative nitrogen balance leading to possible growth disruptions and muscle injuries. Recently, Friedlander et al. [29] indicated that a 3-week caloric restriction alters protein metabolism (leucine turnover and oxidation) in normal-weight young men.

\section{Carbohydrate}

The dietary reference intakes for carbohydrate are based on the amount needed to provide glucose to essential tissues (such as the brain) and do not consider the needs of muscle or liver glycogen replacement. In adults, the performance in prolonged or repeated high-intensity exercise is linked to the total glycogen stores since carbohydrate is the limiting fuel for maintaining the work rate $[30,31]$. In pre-pubertal children, glycolytic capacity is supposed to be less efficient than in adolescent or adult subjects, which induces an enhanced fat utilization during prolonged exercise in young athletes [32]. Whether or not young competitors benefit from a high level of carbohydrate intake has still to be determined. The recommended carbohydrate intake is $50-60 \%$ of the total daily energy intake with only $10 \%$ of simple sugars [33].

Gymnasts or ballet dancers believe that carbohydrates are high-calorie foods. Although the mean intake of carbohydrates in gymnasts, ballerinas, figure skaters, for example, is $\pm 50 \%$ of the total energy intake, it is predominantly with simple sugars rather than complex carbohydrates $[8,17,24,27,34]$. These nutritional surveys indicate that the preference for sweet flavors is not well adapted to 
increase muscle and liver glycogen stores. In weight-class sports, the restricted diet might also induce a significant decrease in muscle and liver glycogen content just before the competition [5].

\section{Lipid}

There is no adequate intake or recommended daily allowance set for total lipids but the adequate intake levels exist with regard to essential fatty acids, linoleic and linolenic acids (n-3 and n-6; table 1).

It is recommended that $30 \%$ of the total energy intake comes from fats in children or adolescents [1,33]. Although children use proportionally more fat as an energy source during prolonged exercise than adults, there are no data to suggest that they need a greater lipid intake.

Concerning the purpose of weight control or weight restriction, it is usual to suggest a decrease in lipid consumption. A total energy intake decreased by fat reduction may be a dangerous strategy in children or adolescent athletes. Indeed, a minimal amount of body fat is required to ensure metabolic and hormonal adaptations. The recommended level for sustaining health and fitness is $7 \%$ for males and $14 \%$ for females [35]. The reduction, or even the exclusion, of fat products is an aberration involving monounsaturated and polyunsaturated fat deficiencies. Furthermore, fat products such as dairy food and red meat contain high-quality protein, calcium, magnesium, iron, zinc, chromium, vitamin $B_{12}$, fat-soluble vitamins, etc., which are necessary to optimize growth. All the nutritional surveys on aesthetic sports, including ballet dancers, figure skaters, gymnasts and rhythmic gymnasts, indicate an insufficient lipid intake [8, 11, 17, 24, 27]. In weight-class sports, the fat distribution widely oscillates between the 'weight-loss' and 'weight-making' periods ('yo-yo' diet). As a consequence, the body fat percentage is perpetually modified which probably disrupts lipid metabolism during the growing state.

\section{Micronutrients}

Inadequate energy intakes are generally accompanied by marginal micronutrient intakes (minerals and vitamins). Indeed, in studies in which young athletes reported caloric restriction, micronutrients failed to meet recommendations $[5,6,8,17,24,34,36,37]$. Studies surveying dietary intake in active children and adolescents or in young athletes commonly identify deficiencies of two important micronutrients: calcium and iron. These micronutrients are critical not only for good health but also in optimizing athletic performance. Iron functions as a component of a number of proteins, including enzymes, he-
Table 1. Adequate intake levels for linoleic and linolenic acids

\begin{tabular}{lll}
\hline \multirow{2}{*}{ Age } & \multicolumn{2}{l}{ Fatty acid, g/day } \\
\cline { 3 - 3 } & linoleic acid & linolenic acid \\
\hline $\begin{array}{l}\text { 9-13 years } \\
\text { Boys }\end{array}$ & 12 & 1.2 \\
Girls & 10 & 1.0 \\
14-18 years & & 1.6 \\
Adolescent boys & 16 & 1.1 \\
Adolescent girls & 11 & \\
\hline
\end{tabular}

moglobin and myoglobin, the latter being important for the transport of oxygen to tissues throughout the body for metabolism. Iron deficiency induces anemia and impairs performance. Calcium is also an important micronutrient for the development of bone mass, a process that may protect against osteoporosis in adulthood. Over $99 \%$ of total body calcium is found in teeth and bones. The remainder is present in blood, extracellular fluid, muscle and other tissues, where it plays a role in mediating vascular contraction and vasodilatation, muscle contraction, nerve transmission and glandular secretion.

Puberty increases the requirements for iron and calcium due to increases in hemoglobin mass, tissue deposition, growth spurt, and the onset of menstruation in females. In sports with energy restriction, dietary calcium and iron are very low $[38,39]$ since young athletes shun dairy foods and red meat either from concern over fat intake or the desire for a vegetarian diet.

\section{Fluids and Exercise}

Hydration status prior to participating in physical activity or sports is an important indicator of performance and endurance, and may limit injuries in adults as well as children or adolescents. Fluid intake is recommended prior to, during and at the end of exercise. Fluid deficits at the end of physical activity should be replaced based on weight loss.

Scientific information on weight-class sports remains scarce with regard to dehydration strategies. However, from a practical point of view, these athletes restrict all fluids before the competition (water, sodas, coffee, soup, etc.) and, in addition, by using plastic underwear, they generally sweat during intensive exercises to stimulate water-weight loss. Other strategies such as saunas, diuretics, vomiting are usually experimented with in the attempt to 'make weight' $[5,28]$. The expected benefit of fluid restric- 
tion and acute dehydration strategies appears to be a rapid weight loss that allows the athletes to compete in a specific category. This strategy, as shown below, is not without consequences.

\section{Potential Consequences on Health}

The difficulty here is to establish causality between food and fluid restrictions and 'health' effects. Indeed, the total interaction between genetic and environmental factors (as nutrition) make the demonstration difficult. However, further studies support the explanation of potentially negative health effects induced by weight restriction in child and/or adolescent athletes.

\section{Growth and Maturation}

Despite the 'normal' short stature of elite gymnasts, rhythmic gymnasts or ballet dancers and the obvious health benefits of physical activity during growth, there is a concern that competitors of 'aesthetic sports' involved in high-level training programs may be at risk of adverse effects on growth and maturation. Indeed, in the absence of sufficient nutrition to compensate for the increased level of physical activity, the energy demands of training may compete with those of the cellular processes underlying normal growth and maturation for available energy, especially during the adolescent growth spurt [40].

For example, female gymnasts have less fat mass than controls and are also significantly shorter and lighter for their age, with differences more important among older, advanced level gymnasts [41]. Most of the time, sexual maturation is delayed in male or female gymnasts compared with their less active twins and/or siblings. Even if longitudinal growth studies offer more insight than crosssectional data, they still do not prove causation [42]. However, most of them indicate attenuated growth and delayed maturation in young female athletes involved in intense training programs, and numerous data indicate catch-up growth when the total amount of training is decreased and/or when the diet is sufficient [for details, see 42]. Frequent reports indicate energy restriction among adolescent female athletes at an advanced competitive level. This mechanism could explain the adverse effect on growth and maturation since the pubertal growth spurt is sensitive to nutritional factors. The mechanisms between food restriction and attenuated growth and maturation in children and adolescents are, in part, due to lesser circu- lating concentrations of growth-related hormones. Indeed, we know that chronic caloric and protein restrictions decrease the level of insulin-like growth factor-1 (IGF-1) [43]. As compared to controls or swimmers, IGF1 plasma levels are lower in young female gymnasts and are associated with insufficient energy intakes, delayed maturation and disrupted growth [44-46]. In contrast, IGF-1 plasma concentrations are not reduced in pre- and early-pubertal male gymnasts as compared to controls [47], but it is well known that the limited dietary intake is always more pronounced in girls.

\section{Body Composition}

Body composition differs according to the sport. In sports imposing weight restriction, there is variability in the relative body fat and lean body weight measures between aesthetic sports and weight-class sports since weight fluctuations appear in the second category.

\section{Body Composition in Aesthetic Sports}

Most of the time athletes who participate in sports in which appearance is an important factor for success are very thin since they consciously initiate a restrained diet to maintain a pre-pubertal physique with low body weight and low fat mass. As a consequence, extensive literature has shown that pre-, early-pubertal and college-age gymnasts, rhythmic gymnasts or ballet dancers are characterized by a low or very low percentage of body fat [for review, see 48]. Paradoxically, studies in athletes or non-athletes have demonstrated that the human adaptive response to energy restriction is a reduction in the resting metabolic rate, with a possible increase in fat storage [49]. For this reason, it becomes more and more difficult for these athletes to keep a low body fat mass, and then when competition ends, an alteration in adipose tissue is usually observed with an increase in total fat cell size and/or fat cell number [15].

Generally, energy imbalance created by a high level of physical activity and diet restriction is associated with lower bone density [49]. However, even if calcium intakes are reduced in aesthetic athletes such as gymnasts, figures skaters, ballet dancers or rhythmic gymnasts, these young female and male athletes have a significantly higher bone mineral density than other athletic groups or non-athletic control groups [48]. Both genetics and also the strain on bone (repeated jumps and dismounts) contribute to higher bone mineral density. Thus, whatever the nutritional intakes, bone mineral and even bone size are elevat- 
ed in elite athletes involved in very high impact activities.

\section{Body Composition in Weight-Class Sports}

In sports with specific weight categories such as wrestling, judo, etc., weight fluctuations are rapid, frequent and large. Thus, body composition may be regularly modified. Weight losses over the short-term are predominantly composed of water, fat, protein, and glycogen. When the athletes lose weight and fat stores, the distribution of body fat may change. With the duration of energy restriction, the contribution of fat stores to total weight lost increases substantially. However, most of the time the young athletes carry out a rapid diet and lose weight over short periods, which leads to significant losses of lean tissue and water $[5,15]$. Reducing the magnitude of energy deficit and increasing the duration of the weight loss period should minimize the loss of lean tissue and maximize the loss of fat. When athletes lose and regain weight, fat stores may be lost and then regained in different areas of the body [15]. If fat is lost from one site and regained in another, the distribution of fat could be modified even if the total fat remains similar. Little is known about weight gain patterns in former weight-class athletes, but later on the 'yo-yo diet' could induce an elevated waist/hip ratio indicating a risk of cardiovascular diseases as in obese people.

\section{Food Efficiency}

Food deficiency can be defined as the ratio of weight change to ingested calories. It represents an index of how much a person must eat to maintain a given weight or body composition. If food efficiency increases, the caloric intake necessary to sustain $1 \mathrm{~kg}$ of body weight decreases. From different studies looking at nutritional intakes and body composition in young male and female athletes, Brownell et al. [15] speculated that food efficiency could be enhanced in athletes with low or fluctuating weights. This mechanism is probably a physiological adaptation facilitating energy stores as a vital process. However, when caloric intake is increased, weight gain could rapidly appear. Anecdotally, some female gymnasts complain that keeping their weight low becomes more and more difficult leading them into a chronic struggle.

\section{Menstrual Dysfunction and Reproductive Capacity}

Dixon et al. [50] suggested that high levels of physical activity result in an increase in the secretion of endorphins, and this in combination with caloric restriction produces an abnormal regulation of hypothalamic activity. Dysregulation of the hypothalamus sparks off the decrease in the pulsatile frequency of gonadotropin secretion (follicle-stimulating hormone, luteinizing hormone) and frequently induces retardation in pubertal maturation and consequently oligo- or amenorrhea [8]. Regulation of the hypothalamus-hypophysis varies greatly from one sport to another. It is well known that elite gymnasts tend to have a delayed age at menarche and menstrual dysregulation (amenorrhea, oligomenorrhea, anovulation, luteal phase deficiency) due to hormonal alterations caused by dieting and the training program [51]. If amenorrhea represents the most extreme form of menstrual dysfunction, other forms can also result in suppressed estrogen levels and affect bone health and fertility. Thus, physically active girls and adolescent females performing aesthetic sports can theoretically develop the 'female athlete triad, a syndrome consisting of three components: disordered eating, amenorrhea and osteoporosis (even if the third one is less usual in high-impact activities as shown above).

Suppressed or decreased testosterone levels in males may be the parallel of menstrual dysfunction in females. Strauss et al. [52] found low serum testosterone levels in male wrestlers, especially when the percent body fat dropped below 5\%. Levels returned to normal after the season when weight increased. Thus, low body weight, low body fat, undernutrition, and/or a high level of training may pose a threat to the reproductive capacity of male athletes.

\section{Iron Status and Anemia}

Low levels of blood hemoglobin (13-14 g/100 ml in males and $12 \mathrm{~g} / 100 \mathrm{ml}$ in females) in addition to low hematocrit and ferritin $(<20 \mu \mathrm{g} / \mathrm{l})$ levels are frequently observed in trained athletes. These parameters define the concept of 'sports anemia' [53]. The hemoglobin mass increases with puberty. To this end and due to tissue deposition, growth spurt and onset of menstruation in females, the iron requirement is more elevated during the pubertal period [33]. Low iron levels may be due to mechanical hemolysis, intestinal bleeding, hematuria, sweating, low iron intake or poor intestinal absorption [53]. The result- 
ing decrease in blood gas transport and muscle enzyme activity impairs performance. Few studies have examined iron status in adolescent athletes, but it seems that these athletes, as adults, are also prone to non-anemic iron deficiency $[54,55]$. On the other hand, evidence of depleted iron stores (low ferritin levels) is reported in female and male gymnasts [38].

\section{Injuries}

Many investigations have examined injuries in young elite gymnasts. Retrospective and prospective studies show that injury rates for female gymnasts are high and positively associated with the performance level. Acute injuries (e.g. stress fractures and ligament sprains) to the feet and toes are common as are ankle injuries [48]. Some of these acute injuries could be due to dietary restriction since it is well known that low estrogen levels, insufficient protein and calcium intakes, combined with a late menarche, potentially lead to an increased rate of stress fractures [56].

During weight-loss strategies in weight-class sports, it is usual to observe musculoskeletal injuries due to fluid deprivation before competition [35]. The possibility of suffering a heat injury is also present if the competition is performed in a severely heated environment.

\section{Dehydration Effects}

Severe weight reduction might actually impair physiological functions. For instance dehydration could impair the kidneys by reducing plasma flow and filtration. Young wrestlers also have reported instances of irritability, constipation and 'feeling flat' [37]. The effects of rapid weight loss and dehydration on physiological performance are well documented [35]. This practice might cause: a reduction in muscle strength and anaerobic power capacity; increased resting and submaximal heart rate; decreased cardiac stroke volume resulting in a decreased ability to sustain work at a constant rate; lower oxygen consumption; impaired thermoregulatory processes; lower plasma and blood volume; depletion in muscle and possibly liver glycogen; difficulty in glucose homeostasis; altered hormonal status; reduced immune function, and so forth [35]. In addition, in vitro research has suggested that dehydration of cells can lead to the initiation of protein and glycogen breakdown as a means to adjust cellular osmolarity in response to a decreased intracellular fluid volume [57].

\section{Eating Disorders}

Eating disorders may be defined as eating or not eating in response to an external cue rather than an internal one. Eating disorders in the female athletic population are receiving increasing attention. Athletes performing in sports that require leanness and/or a specific body weight are more prone to develop eating disorders than other athletes [58]. Thus, competitive rhythmic sport gymnasts, gymnasts, ballet dancers, figure skaters, for example, are accused of promoting an unphysiologic weight reduction which may progress to manifest anorexia and/or bulimia nervosa [58]. The enormous pressure on young athletes to be successful and achieve an ideal body weight may explain this fact. Thus, athletes in 'thin-build' sports report greater body dissatisfaction, low self-esteem and more persistent dieting than other athletes. The inability to control weight and body shape can lead to frustration, guilt, and even despair which may induce social and emotional disturbances.

\section{Morbidity and Mortality}

The dietary practices followed by some athletes may increase the risk of acute or chronic diseases. Aside from the specific quality of the diet (saturated fats, simple sugars, sodium, etc.), body weight patterns could also influence health. It is well known that chronic calorie restriction reduces the risk of certain cancers [59] and decreases coronary disease, hypertension and diabetes. However, athletes with low weights and eating disorders may suffer from important nutritional deficiencies (e.g. vitamins, minerals, essential amino acids, essential fatty acids) which may alter metabolic and organic functions. For example, patients with anorexia nervosa have a greater QT dispersion than constitutionally thin and normal-weight females due to very low potassium levels (QT dispersion was defined as the difference between the longest and the shortest QT interval occurring in the 12-lead ECG) [60]. In the same way, repeated bouts of loss and regain may create different negative effects on health. Indeed, weight loss is associated with decreased blood pressure, and gain with increased pressure. The increase period being more important that the decrease period, blood pressure may be affected. Furthermore, different studies have suggested that renal ischemia may result from weight cycling in wrestlers, which could predispose them to later hypertension [15]. 


\section{Conclusion}

As shown in this review, the consequences on health of sport-imposed weight restriction in childhood are numerous and sometimes irreversible. To avoid these dramatic effects, we recommend that the nutritional status of highly active young athletes be carefully monitored, re- gardless of their age, sport and gender, especially those engaged in sports characterized by a limited food intake (aesthetic sports) or irregular food consumption (weightclass sports). A psychological approach and nutritional education for athletes, trainers, parents, etc., should complete the dietetic advice made by a sport dietician or nutritionist.

\section{References}

1 DRI: Dietary Reference Intakes for Energy, Carbohydrate, Fiber, Fat, Fatty Acids, Cholesterol, Protein, and Amino Acids (Macronutrients). Washington, National Academy Press, 2002.

2 Tveit-Milligan P, Spindler AA, Nichols JE: Genes and gymnastics: a case study of triplets. Sports Med Training Rehab 1993;4:47-52.

-3 Lindholm C, Hagenfeldt K, Ringertz BM: Pubertal development in elite juvenile gymnasts. Effects of physical training. Acta Obstet Gynecol Scand 1994;73:269-273.

-4 Steen SN, Brownell KD: Patterns of weight loss and regain in wrestlers: has the tradition changed? Med Sci Sports Exerc 1990;22:762_ 768.

5 Boisseau N, Vera-Perez S, Poortmans JR: Food and fluid intake in adolescent female judo athletes before competition. Pediatr Exerc Sci 2005; 17:62-71

-6 Oppliger RA, Steen SA, Scott JR: Weight loss practices of college wrestlers. Int J Sport Nutr Exerc Metab 2003;13:29-46.

7 Steen SN, Oppliger RA, Brownell KD: Metabolic effects of repeated weight loss and regain in adolescent wrestlers. JAMA 1988;260:4750.

8 Weimann E, Witzel C, Schwidergall S, Bohles HJ: Peripubertal perturbations in elite gymnasts caused by sport specific training regimes and inadequate nutritional intake. Int J Sports Med 2000;21:210-215.

-9 Theintz GE, Howald H, Allemann Y, Sizonenko PC: Growth and pubertal development of young female gymnasts and swimmers: a correlation with parental data. Int J Sports Med 1989;10:87-91.

10 Schwidergall S, Weimann E, Witzel C, Molenkamp G, Brehl S, Bohles H: Nutritional behaviour of female and male high performance gymnasts. Wien Med Wochenschr 1988;148: 243-244.

11 Lindholm C, Hagenfeldt K, Hagman U: A nutrition study in juvenile elite gymnasts. Acta Paediatr 1995;84:273-277.

12 Kiningham RB, Gorenflo DW: Weight loss methods of high school wrestlers. Med Sci Sports Exerc 2001;33:810-813.
13 Gurd B, Klentrou P: Physical and pubertal development in young male gymnasts. J Appl Physiol 2003;95:1011-1015.

14 Georgopoulos N, Markou K, Theodoropoulou A, Paraskevopoulou P, Varaki L: Growth and pubertal development in elite female rhythmic gymnasts. J Clin Endocrinol Metab 1999;84:4525-4530.

15 Brownell KD, Steen SN, Wilmore JH: Weight regulation practices in athletes: analysis of metabolic and health effects. Med Sci Sports Exerc 1987; 19:546-556.

16 Baxter-Jones AD, Helms P, Maffulli N, BainesPreece JC, Preece M: Growth and development of male gymnasts, swimmers, soccer and tennis players: a longitudinal study. Ann Hum Biol 1995;22:381-394.

17 Boisseau N, Persaud C, Jackson AA, Poortmans JR: Training does not affect protein turnover in pre- and early pubertal female gymnasts. Eur J Appl Physiol 2005;94:262267.

18 Fogelholm GM, Kukkonen-Harjula TK, Taipale SA, Sievänen HT, Oja P, Vuori IM: Resting metabolic rate and energy intake in female gymnasts, figure-skaters and soccer players. Int J Sports Med 1995;16:551-556.

19 Bass S, Bradney M, Pearce G, Hendrich E, Inge $\mathrm{K}$ : Short stature and delayed puberty in gymnasts: influence of selection bias on leg length and the duration of training on trunk length. J Pediatr 2000;136:149-155.

20 Zonderland ML, Claessens AL, Lefevre J, Philippaerts R, Thomis M: Delayed growth and decreased energy intake in female gymnasts; in Armstrong N, Kirby B, Welsman J (eds): Children and Exercise XIX: Promoting Health and Well-Being: Proceedings of the XIXth International Symposium of the European Group of Pediatric Work Physiology. London, E\&FN Spon, 1997, pp 553-556.

21 Poortmans JR: Protein metabolism; in Poortmans JR (ed): Principles of Exercise Biochemistry. Basel, Karger, 2004, pp 227-278.

22 FAO/WHO: Joint Expert Committee: Energy and Protein Requirements. Geneva, World Health Organization, 1986

23 Martin A: Apports nutritionnels conseillés pour la population française. Paris, Tec \& Doc 2001.
24 Cupisti A, D'Alessandro S, Castrogiovanni S, Barale E, Morelli E: Nutrition survey in elite rhythmic gymnasts. J Sports Med Phys Fit 2000;40:350-355.

25 Weimann E, Blum WF, Witzel C, Schwidergall S, Bohles HJ: Hypoleptinemia in female and male elite gymnasts. Eur J Clin Invest 1999;29: 853-860.

26 Fogelholm GM, Kukkonen-Harjula TK, Taipale SA, Sievanen HT, Oja P, Vuori IM: Resting metabolic rate and energy intake in female gymnasts, figure-skaters and soccer players. Int J Sports Med 1995;16:551-556.

27 Benson J, Gillien DM, Bourdet K, Loosli AR: Inadequate nutrition and chronic calorie restriction in adolescent ballerinas. Phys Sportmed 1985;13:79-90.

28 Horswill CA, Park SH, Roemmich JN: Changes in the protein nutritional status of adolescent wrestlers. Med Sci Sports Exerc 1990;22: 599-604.

29 Friedlander AL, Braun B, Pollack M, MacDonald JR, Fulco CS: Three weeks of caloric restriction alters protein metabolism in normal-weight, young men. Am J Physiol Endocrinol Metab 2005;289:E446-E455.

- 30 Coyle EF, Coyle E. Rating carbohydrates that speed recovery from training. Phys Sportsmed 1993;21:111-123.

31 Costill DL, Sherman WM, Fink WJ, Maresh C, Witten M, Miller JM: The role of dietary carbohydrate in muscle glycogen resynthesis after strenuous running. Am J Clin Nutr 1981; 34:1831-1836.

- 32 Boisseau N, Delamarche P: Metabolic and hormonal responses to exercise in children and adolescents. Sports Med 2000;30:405422.

33 ANC: Apports nutritionnels recommandés (ANC) pour la population française. Paris, Tec \& Doc, 2001

34 Delistraty DA, Reisman EJ, Snipes MG: A physiological and nutritional profile of young female figure skaters. J Sports Med Phys Fit 1992;32:149-155.

35 Oppliger RA, Case HS, Horswill CA, Landry GL, Shelter AC: American College of Sports Medicine position stand. Weight loss in wrestlers. Med Sci Sports Exerc 1996;28:ix-xii. 
-36 Moffatt RJ: Dietary status of elite female high school gymnasts: inadequacy of vitamin and mineral intake. J Am Diet Assoc 1984;84: 1361-1363.

-37 Freischlag J: Weight loss, body composition, and health of high school wrestlers. Phys Sportmed 1984;12:121-126.

38 Constantini NW, Eliakim A, Zigel L, Yaaron M, Falk B: Iron status of highly active adolescents: evidence of depleted iron stores in gymnasts. Int J Sport Nutr Exerc Metab 2000;10: $62-70$.

39 Kirchner EM, Lewis RD, O’Connor PJ: Bone mineral density and dietary intake of female college gymnasts. Med Sci Sports Exerc 1995; 27:543-549.

40 Borer KT: The effects of exercise on growth. Sports Med 1995;20:375-397.

41 Caine D, Lewis R, O'Connor P, Howe W, Bass $\mathrm{S}$ : Does gymnastics training inhibit growth of females? Clin J Sport Med 2001;11:260-270.

-42 Caine D, Bass S, Daly R: Does elite competition inhibit growth and delay maturation in some gymnasts? Quite possibly. Pediatr Exerc Sci 2003;15:360-372.

-43 Smith WJ, Underwood LE, Clemmons DR: Effects of caloric or protein restriction on insulin-like growth factor-I (IGF-I) and IGFbinding proteins in children and adults. J Clin Endocrinol Metab 1995;80:443-449.

44 Theintz GE: Endocrine adaptation to intensive physical training during growth. Clin Endocrinol 1194;41:267-272.
45 Jahreis G, Kauf E, Frohner G, Schmidt HE: Influence of intensive exercise on insulin-like growth factor I, thyroid and steroid hormones in female gymnasts. Growth Regul 1991;1:9599.

46 Bass S, Pearce G, Bradney M, Hendrich E, Delmas PD: Exercise before puberty may confer residual benefits in bone density in adulthood: studies in active prepubertal and retired female gymnasts. J Bone Miner Res 1998;13: 500-507.

47 Daly RM, Rich PA, Klein R, Bass SL: Short stature in competitive prepubertal and early pubertal male gymnasts: the result of selection bias or intense training? J Pediatr 2000;137: 510-516.

48 O'Connor PJ, Lewis RD, Boyd A: Health concerns of artistic women gymnasts. Sports Med 1996;21:321-325.

49 Deutz RC, Benardot D, Martin DE, Cody MM: Relationship between energy deficits and body composition in elite female gym nasts and runners. Med Sci Sports Exerc 2000; 32:659-668

50 Dixon G, Eurman P, Stern BE, Schwartz B, Rebar RW: Hypothalamic function in amenorrheic runners. Fertil Steril 1984;42:377-383.

51 Manore MM: Dietary recommendations and athletic menstrual dysfunction. Sports Med 2002;32:887-901.

52 Strauss RH, Lanese RR, Malarkey WB: Weight loss in amateur wrestlers and its effect on serum testosterone levels. JAMA 1985;254: 3337-3338.
53 Chatard JC, Mujika I, Guy C, Lacour JR: Anaemia and iron deficiency in athletes. Practical recommendations for treatment. Sports Med 1999;27:229-240.

54 Rowland TW: Iron deficiency in the young athlete. Pediatr Clin North Am 1990;37:11531163.

55 Rowland TW, Stagg L, Kelleher JF: Iron deficiency in adolescent girls. Are athletes at increased risk? J Adolesc Health 1991;12:2225.

56 Benson JE, Geiger CJ, Eiserman PA, Wardlaw GM: Relationship between nutrient intake, body mass index, menstrual function, and ballet injury. J Am Diet Assoc 1989;89:5863.

57 Petrie HJ, Stover EA, Horswill CA: Nutritional concerns for the child and adolescent competitor. Nutrition 2004;20:620-631.

58 Sundgot-Borgen J: Eating disorders, energy intake, training volume, and menstrual function in high-level modern rhythmic gymnasts. Int J Sport Nutr 1996;6:100-109.

59 Kritchevsky D, Weber MM, Buck CL, Klurfeld DM: Calories, fat and cancer. Lipids 1986;21: 272-274.

60 Franzoni F, Mataloni E, Femia R, Galetta F: Effect of oral potassium supplementation on QT dispersion in anorexia nervosa. Acta Paediatr 2002;91:653-656 